\title{
Salt partitioning on freezing closed- basin lakes in Mongolia: Implications for subsurface brine reservoirs on icy bodies in the Solar system
}

\author{
MASAHIRO YODA ${ }^{1,2}$, YASUHITO SEKINE ${ }^{3,4}$, KEISUKE
} FUKUSHI $^{4}$, TAKUMA KITAJIMA ${ }^{5}$, BAASANSUREN

GANKHUREL $^{5}$, DAVAADORJ DAVAASUREN ${ }^{6}$, TUVSHIN

GERELMAA $^{6}$, SHUUKHAAZ GANBAT ${ }^{5}$, DAIGO SHOJI ${ }^{7}$, YOSHIO TAKAHASHI ${ }^{2}$ AND MIKHAIL ZOLOTOV ${ }^{8}$

${ }^{1}$ Earth-Life Science Institute, Tokyo Institute of Technology

${ }^{2}$ The University of Tokyo

${ }^{3}$ Tokyo Institute of Technology, Earth-Life Science Institute

${ }^{4}$ Institute of Nature and Environmental Technology, Kanazawa University

${ }^{5}$ Division of Earth and Environmental Sciences, Graduate School of Natural Science and Technology, Kanazawa University

${ }^{6}$ Department of Geography, The National University of Mongolia

${ }^{7}$ Institute of Space and Astronautical Science, Japan Astronautical Exploration Agency, Sagamihara, Kanagawa

${ }^{8}$ Arizona State University

Presenting Author: yodamasa@elsi.jp

Ceres and Europa would have possessed near-surface brine reservoirs, which may be a source of localized salts on the surfaces. Several processes of salt transport from the subsurface have been hypothesized. However, the salt partitioning between subsurface brines and mineralization upon freezing of the brines are insufficiently investigated through experiments or field observations.

Here, we report results of winter field surveys to ice-covered, closed-basin saline lakes of Orog and Olgoy Lakes in Mongolia. The surface ice exhibited complex morphology with pressurized ridges formed by compressive forces and wet cracks formed by extensional forces. Wet cracks allowed transportation of salinity to the icy surface. We measured the vertical salinity profiles in lake ice without the cracks. Using a coupled model of mass balance and low-temperature aqueous chemistry (the FREZCHEM code), we show that the observed vertical profiles of salinity in the ice layer can be explained by capturing of lake water within pores of ice grains. To explain high $\mathrm{Mg}^{2+}$ and $\mathrm{Ca}^{2+}$ concentrations of in the bottom water, we suggest that metastable phase of carbonates, monohydrocalcite and amorphous $\mathrm{Mg}$ carbonate, controlled $\mathrm{Ca}^{2+}, \mathrm{Mg}^{2+}$, and $\Sigma \mathrm{CO}_{2}$ concentrations of the freezing bottom lake water. This implies that if metastable carbonates control $\mathrm{Ca}^{2+}, \mathrm{Mg}^{2+}$, and $\Sigma \mathrm{CO}_{2}$ concentrations in subsurface brine reservoirs on icy bodies (e.g., Ceres), these concentrations would become one order of magnitude higher than those with a consideration of stable carbonates. 